\title{
Spatial clustering of livestock Anthrax events associated with agro-ecological zones in Kenya, 1957-2017
}

Leonard M. Nderitu ${ }^{1,2}$, John Gachohi ${ }^{2,3^{*}}$ (D), Frederick Otieno ${ }^{4}$, Eddy G. Mogoa ${ }^{5}$, Mathew Muturi ${ }^{6,4}$, Athman Mwatondo ${ }^{6,4}$, Eric M. Osoro ${ }^{2}$, Isaac Ngere ${ }^{2}$, Peninah M. Munyua ${ }^{7}$, Harry Oyas $^{8}$, Obadiah Njagi ${ }^{8}$, Eric Lofgren', Thomas Marsh', Marc-Alain Widdowson ${ }^{7,9}$, Bernard Bett ${ }^{4}$ and M. Kariuki Njenga ${ }^{1,2}$

\begin{abstract}
Background: Developing disease risk maps for priority endemic and episodic diseases is becoming increasingly important for more effective disease management, particularly in resource limited countries. For endemic and easily diagnosed diseases such as anthrax, using historical data to identify hotspots and start to define ecological risk factors of its occurrence is a plausible approach. Using 666 livestock anthrax events reported in Kenya over 60 years (1957-2017), we determined the temporal and spatial patterns of the disease as a step towards identifying and characterizing anthrax hotspots in the region.
\end{abstract}

Methods: Data were initially aggregated by administrative unit and later analyzed by agro-ecological zones (AEZ) to reveal anthrax spatio-temporal trends and patterns. Variations in the occurrence of anthrax events were estimated by fitting Poisson generalized linear mixed-effects models to the data with AEZs and calendar months as fixed effects and sub-counties as random effects.

Results: The country reported approximately 10 anthrax events annually, with the number increasing to as many as 50 annually by the year 2005. Spatial classification of the events in eight counties that reported the highest numbers revealed spatial clustering in certain administrative sub-counties, with $12 \%$ of the sub-counties responsible for over 30\% of anthrax events, whereas 36\% did not report any anthrax disease over the 60-year period. When segregated by AEZs, there was significantly greater risk of anthrax disease occurring in agro-alpine, high, and medium potential AEZs when compared to the agriculturally low potential arid and semi-arid AEZs of the country $(p<0.05)$. Interestingly, cattle were $>10$ times more likely to be infected by $B$. anthracis than sheep, goats, or camels. There was lower risk of anthrax events in August $(P=0.034)$ and December $(P=0.061)$, months that follow long and short rain periods, respectively.

Conclusion: Taken together, these findings suggest existence of certain geographic, ecological, and demographic risk factors that promote $B$. anthracis persistence and trasmission in the disease hotspots.

Keywords: Clustering, Livestock, Anthrax, Agro-ecological zones, Kenya

\footnotetext{
* Correspondence: john.gachohi@wsu.edu

${ }^{2}$ Washington State University Global 'Health Program-Kenya, WSU, Nairobi,

Kenya

${ }^{3}$ School of Public Health, Jomo Kenyatta University of Agriculture and

Technology, Nairobi, Kenya

Full list of author information is available at the end of the article
}

(C) The Author(s). 2021 Open Access This article is licensed under a Creative Commons Attribution 4.0 International License, which permits use, sharing, adaptation, distribution and reproduction in any medium or format, as long as you give appropriate credit to the original author(s) and the source, provide a link to the Creative Commons licence, and indicate if changes were made. The images or other third party material in this article are included in the article's Creative Commons licence, unless indicated otherwise in a credit line to the material. If material is not included in the article's Creative Commons licence and your intended use is not permitted by statutory regulation or exceeds the permitted use, you will need to obtain permission directly from the copyright holder. To view a copy of this licence, visit http://creativecommons.org/licenses/by/4.0/. The Creative Commons Public Domain Dedication waiver (http://creativecommons.org/publicdomain/zero/1.0/) applies to the data made available in this article, unless otherwise stated in a credit line to the data. 


\section{Background}

Anthrax is an acute, often fatal disease of animals caused by a soil-borne Bacillus anthracis (B. anthracis) that exists in two forms; the vegetative toxin-producing form, and the dormant spore form that persists in soil for long periods [1, 2]. The disease is endemic in Africa and Asia where domestic and wild herbivores are infected by ingesting or inhaling spores during feeding and in watering points, whereas humans are infected through contact with infected animal carcasses or their products [2-6]. Cutaneous anthrax is the most common form in humans accounting for $95 \%$ of cases $[3,7,8]$. Whereas anthrax has a worldwide distribution, incidence has declined in most developed countries due to livestock vaccination programs and other sanitary measures.

The global incidence of anthrax varies with time and location, triggered by a combination of geographic and ecological factors that support B. anthracis persistence, and the changing animal and human demographics that enhance exposure to the pathogen [9-11]. The World Health Organization (WHO) estimates that $>90 \%$ of human $B$. anthracis infections globally are attributed to contact with or consumption of livestock and their products and approximately 5\% attributed to contact with wildlife [12].

In Kenya, a survey conducted in 2007 reported a human anthrax seroprevalence of $11.3 \%$, with seropositive cases detected in all regions of the country, but ranging from $2 \%$ in the north to $27.5 \%$ in western regions of the country [13]. The Kenya Directorate of Veterinary Services (KDVS) reports more than 10 livestock anthrax events annually that involve humans, and many more livestock anthrax events that do not involve humans [14]. Wildlife anthrax events are reported in over $30 \%$ of Kenyan national conservancies, with $>65 \%$ of them reported during the dry seasons and primarily affecting herbivore species: buffaloes, endangered black and white rhinos and elephants that account for $>50 \%$ of the affected species and attracting profound conservation interests [6]. Anthrax is among the top priority zoonotic diseases in Kenya and, therefore, the government is developing a risk map for the disease to inform prevention and control measures [15]. Here, we reviewed anthrax records among livestock over the past 60 years in order to describe the temporal and spatial patterns of the disease as a step towards identifying ecological zones with high burden of the disease with the ultimate objective of risk mapping to inform anthrax surveillance, management and control.

\section{Methods}

\section{Sources of data}

We collected data on anthrax events between 1957 and 2017 from three sources. First, the disease events database maintained at Veterinary Epidemiology and Economics Unit (VEEU) of the KDVS headquarters in Kabete, Nairobi, provided data for the 2009-2017 period. Second, the livestock disease event records in the former eight provincial headquarters archives provided additional data for the 1957-2009 period. In 2013, the provinces were dissolved, and the country devolved into 47 semi-autonomous counties. Therefore, we also reviewed disease event records at County Departments of Veterinary Services to obtain data for the 2013-2017 period. From the three data sources, we reviewed standard field disease surveillance report forms referred to as Notifiable Disease- 1 form, quarantine records, annual reports, and standard laboratory forms.

\section{Data collection and analysis}

Any livestock death classified as anthrax through clinical or laboratory diagnosis was considered an anthrax event. Using standard guidelines issued by the Kenya's Directorate of Veterinary Services, a clinical diagnosis was made by animal health practitioners across the country as an acute cattle, sheep or goat disease characterized by sudden death with or without bleeding from natural orifices accompanied by absence of rigor mortis. Further, if the carcass was accidentally opened, failure of blood to clot and/or the presence of splenomegaly were included. In pigs, symptoms included swelling of the face and neck with oedema [16]. A laboratory confirmed anthrax event was diagnosed using Gram and methylene blue stains followed by identification of the capsule and typical rodshaped B. anthracis in clinical specimens submitted to the central or regional veterinary investigation laboratories in Kenya [17].

Using a standard Microsoft Excel ${ }^{\circ}$ spreadsheet, we captured location of the anthrax events (administrative locations at sub-county level, and Global Positioning System (GPS) coordinates if available), number and species of animals affected, human involvement, event timelines, and clinical and laboratory diagnosis. Subsequently, we cleaned the data to remove duplication and incomplete entries, resulting in final number of 666 anthrax events for analysis. Using the pivot table function within Microsoft Excel $^{\circ}$, charts of anthrax event trends were drawn, a frequency distribution prepared, and the data used to map the distribution by counties using Quantum Global Information System (QGIS) version 3.4.4 software (https://qgis. org). We used the livestock census data of 2009 to provide denominators for species comparisons where necessary.

\section{Spatial clustering of anthrax events}

To determine whether anthrax events occurred more frequently in certain geographic location, we used data from 8 counties that reported the highest number of anthrax events, aggregated the events by sub-county, and 
expressed this as a percent of the total number of the events in the county. We used percentages instead of raw count of anthrax events in order to have a metric for standardization across sub-counties and counties. Each county consisted of 4-12 sub-counties. Four intervals of anthrax events occurrence were used to classify sub-counties in each county; no occurrence (0\%), low (1-15\%), medium (16-30\%), and high (>30\%) occurrences. Using this classification, choropleth maps for each county were developed in QGIS version 3.4.4 software (https://qgis.org), using different color codes to denote no risk (white), low (beige), medium (brown), and high (maroon) risk of anthrax occurrence [18].

To describe spatial clustering by county, we used 86 anthrax events that had GPS coordinates by assigning each to AEZ and fitting a univariate generalized linear mixed-effects model with the Poisson distribution and log link function. Administratively, Kenya has 47 counties while agriculturally it is divided into seven AEZs based on soil types, landforms, and climatic condition that determine agricultural potential. For ease of analysis, the AEZs were reclassified into 5; (i) agro-alpine, (ii) high and medium potential, (iii) semi arid, (iv) arid, and (v) very arid and desert conditions. For the Poisson mixed effects regression, the AEZ, analyzed as a categorical variable was used as fixed effects and subcounty as random effect outcome variable focusing on the expected number of anthrax events in each AEZ as our outcome variable [19]. For AEZs, we used log transformation (ln) of the livestock population in each AEZ as an offset to account for differences in population sizes and then used STATA software (version 14) to fit a random intercept model accounting for spatial dependency.

\section{Seasonal trends and overall spatio-temporal analyses of anthrax events}

To determine seasonal trends, all 666 historical anthrax events were aggregated over four seasons experienced in the region; dry and hot season (January to March), wet and cool (April to June), dry and cool (July to September), and wet and hot (October to December). Using percentage of anthrax events, four intervals were created to define counties of no occurrence $(0 \%)$, low $(<7 \%)$, medium $(7-$ $10 \%)$, and high $(>10 \%)$ occurrences. Using time series analysis (R software 3.6.3; https://r-forge.r-project.org/ $\mathrm{scm} /$ viewvc.php/pkg/timeSeries/?root=rmetrics), we evaluated periodic component covering the defined seasons between 1957 to 2017 [20]. We further analyzed intraannual variation in the occurrence of the 86 anthrax events using univariate Poisson generalized linear mixedeffects model using principles applied in the above described AEZ model. Here, the calendar month, analyzed as a categorical variable, was used as fixed effects and subcounty as random effect outcome. Figure 1 illustrates the subsets of data employed in the different levels of the analyses. We assessed the overall fit of the models using the chi-square goodness-of-fit tests through computing the sum of the squared deviance and Pearson residuals.

\section{Results}

Spatial distribution of livestock anthrax events in Kenya In the 60-year period (1957 to 2017), 666 livestock anthrax events in 46 of the 47 (97.9\%) counties were identified, of which $17.8 \%$ were laboratory confirmed. Only Turkana County located in the far northwest corner of the country did not report an anthrax event. Eight (17.0\%) counties reported $>20$ events each, most of them located in the south-western and south-central regions of the country including Kiambu county that reported 191 events, Meru, Narok and Nyeri counties that reported 50-60 events, and Murang'a, Nakuru and Nairobi that reported 25-40 events (Fig. 2).

A total of 456 of the 666 (68.5\%) anthrax events had sub-county information, and 163 (77.6\%) of the 210 subcounties in Kenya reported at least one anthrax event since 1957. The highest reporting sub-counties and counties were located in Thika $(n=32)$ in Kiambu County, Keyian $(n=16)$ in Narok County, Kikuyu $(n=$ 15) in Kiambu County, Rongai $(n=13)$ in Nakuru County, Olulunga $(n=13)$ in Narok County, Kabete $(n=$ $12)$ in Kiambu County, and Sotik $(n=12)$ in Bomet County.

\section{Anthrax events trend and seasonality}

Between 1957 and 1996, fewer than 10 livestock anthrax events were reported annually (Fig. 3). Thereafter, the number grew steadily, reaching a peak between 2005 and 2007 period when $>50$ anthrax events were reported annually. There was a decrease in reported events during the 2011-2014 period, attributed to change in government structure to devolved counties (Fig. 3).

As shown in Fig. 4, descriptive time series analysis revealed less seasonal variation in occurrence of anthrax events. The highest number of anthrax events were reported during the hot and dry January to March season (trend factor $=0.25$ ) while the October to December hot and wet season reported the lowest (trend factor $=-0.26$ ). The wet and cool (April to June) yielded a trend factor of 0.22 while that of dry and cool (July to September) was -0.2 .

\section{Involvement of livestock species}

Based on the 2009 census data, Kenya had 64 million livestock, including goats (27 million), cattle (17 million), sheep (17 million), camels (3 million) and pigs (300 thousand) [21]. However, anthrax associated deaths were more frequently reported in cattle than other species, a trend that was maintained across all years (Fig. 5). The 
Database 1: Veterinary Epidemiology and Economics Unit of the Kenya Directorate of Veterinary Services (KDVS) headquarters in Kabete, Nairobi (2009 - 2017)

Database 2: Former eight provincial headquarters archives (1957-2009).

Database 3: County Departments of Veterinary Services (2013-2017).

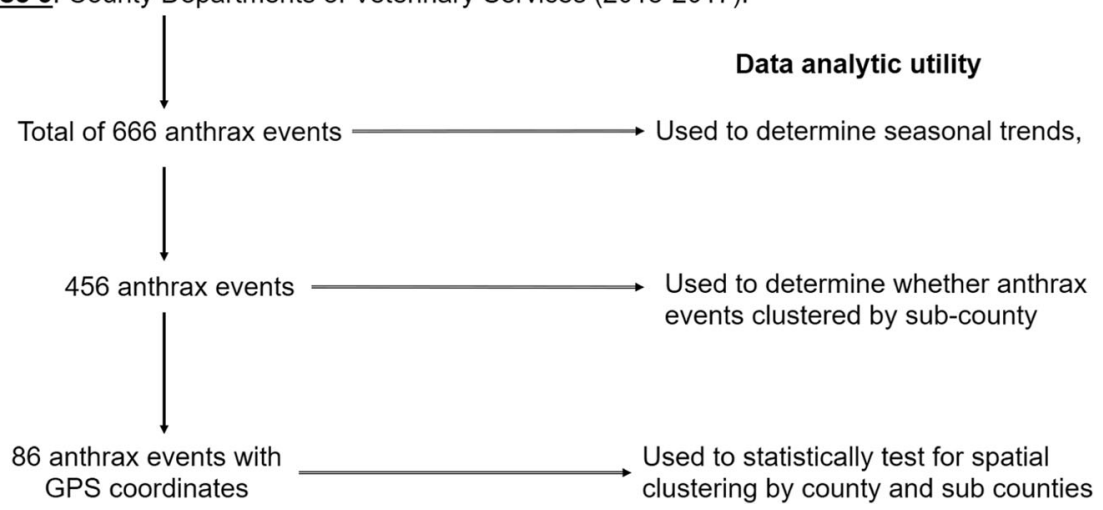

Fig. 1 Flow chart illustrating the subsets of data employed in the different levels of the analyses

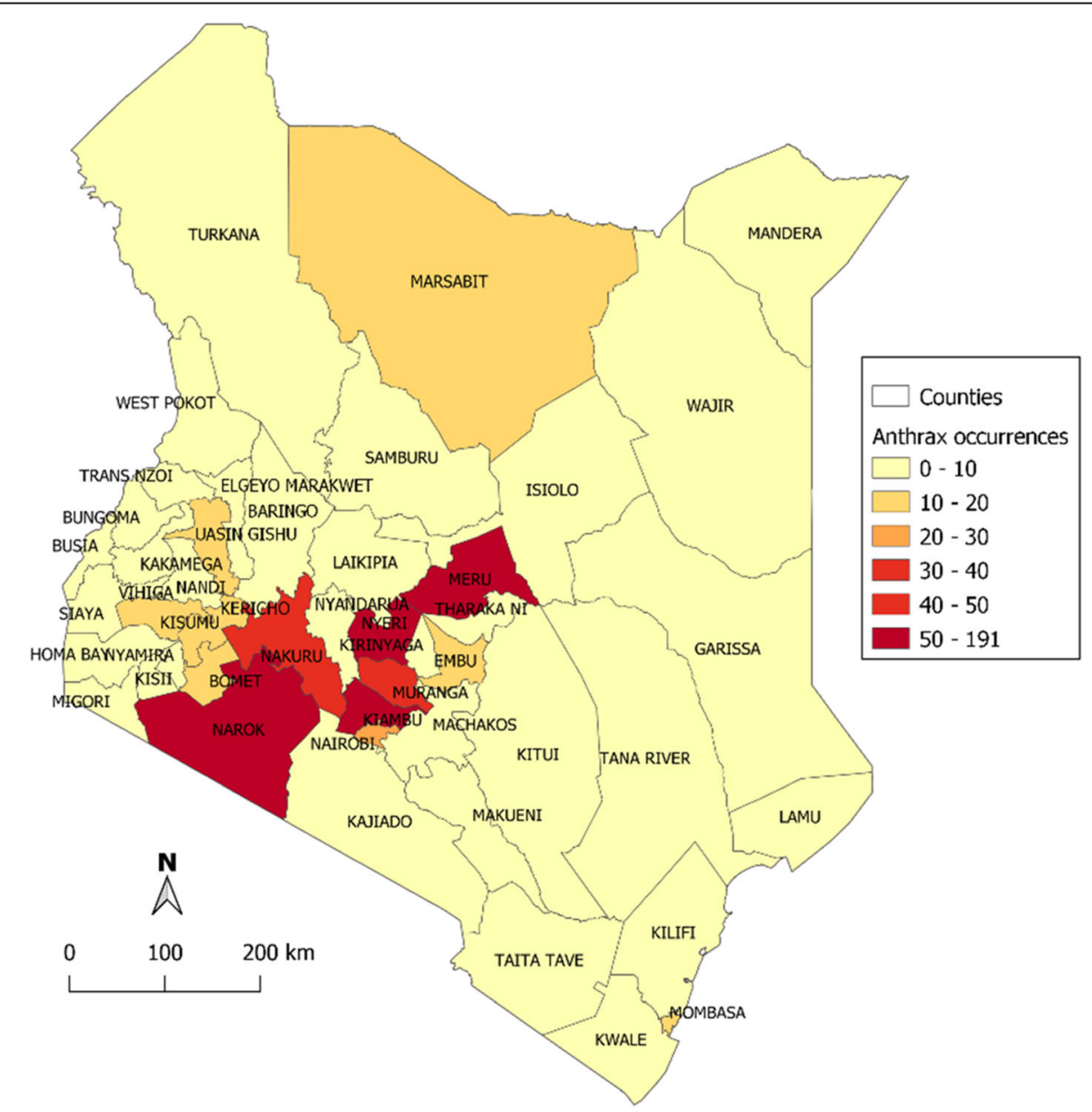

Fig. 2 Spatial distribution of anthrax events in livestock by counties, Kenya 1957-2017 


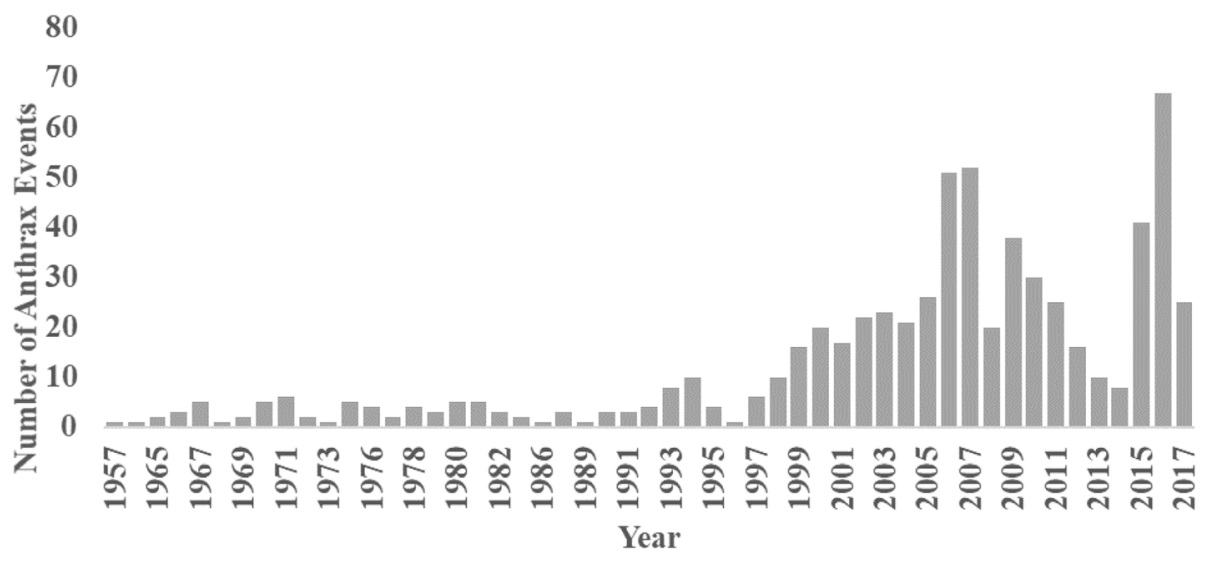

Fig. 3 Trend in reported anthrax events in livestock in Kenya, 1957-2017

ratio of cattle to small ruminant reported anthrax events was between 10:1 and 20:1.

\section{Spatial clustering}

We investigated spatial distribution of anthrax events in eight counties that reported 71.3\% (475/666) of the livestock anthrax events, aggregated into sub-counties. The counties were Kiambu $(n=191$ events), Meru $(n=56)$, Nyeri $(n=53)$, Narok $(n=51)$, Murang'a $(n=39)$, Nakuru $(n=37)$, Nairobi $(n=28)$, and Marsabit $(n=20)$. Of the 69 sub-counties in these counties, $25(36.2 \%)$ reported zero events, whereas $8(11.6 \%)$ reported $>30 \%$ (high risk) anthrax events (Fig. 5). Another 12 (17.4\%) sub-counties reported 16-30\% (medium risk) events whereas $24(34.8 \%)$ sub-counties reported 1-15\% (low risk) events (Fig. 6). This clustering trend was maintained over time as demonstrated by stratification of the data into 20-year periods; 1957-1977, 1978-1997, and 1998-2017. The 20-year period was chosen because it provided the minimum number of observations for adequate and meaningful analyses. Our data showed a larger proportion of anthrax events reported in dry seasons relative to wet seasons, regardless of region of the country or seasonal temperature variations.

Analysis of 86 anthrax events with GPS coordinates (Fig. 7), showed progressive decrease in the number of events from the agro-alpine (highest), high and medium potential, semi-arid, arid, to very arid zones (lowest) as shown in Table 1. The High and Medium potential was used as the referent category since it constituted the largest proportion of events (68.5\%). The likelihood ratio test conducted during the analyses showed that inclusion of sub-county random effect provided a substantially better fit than the standard Poisson regression $(P=$

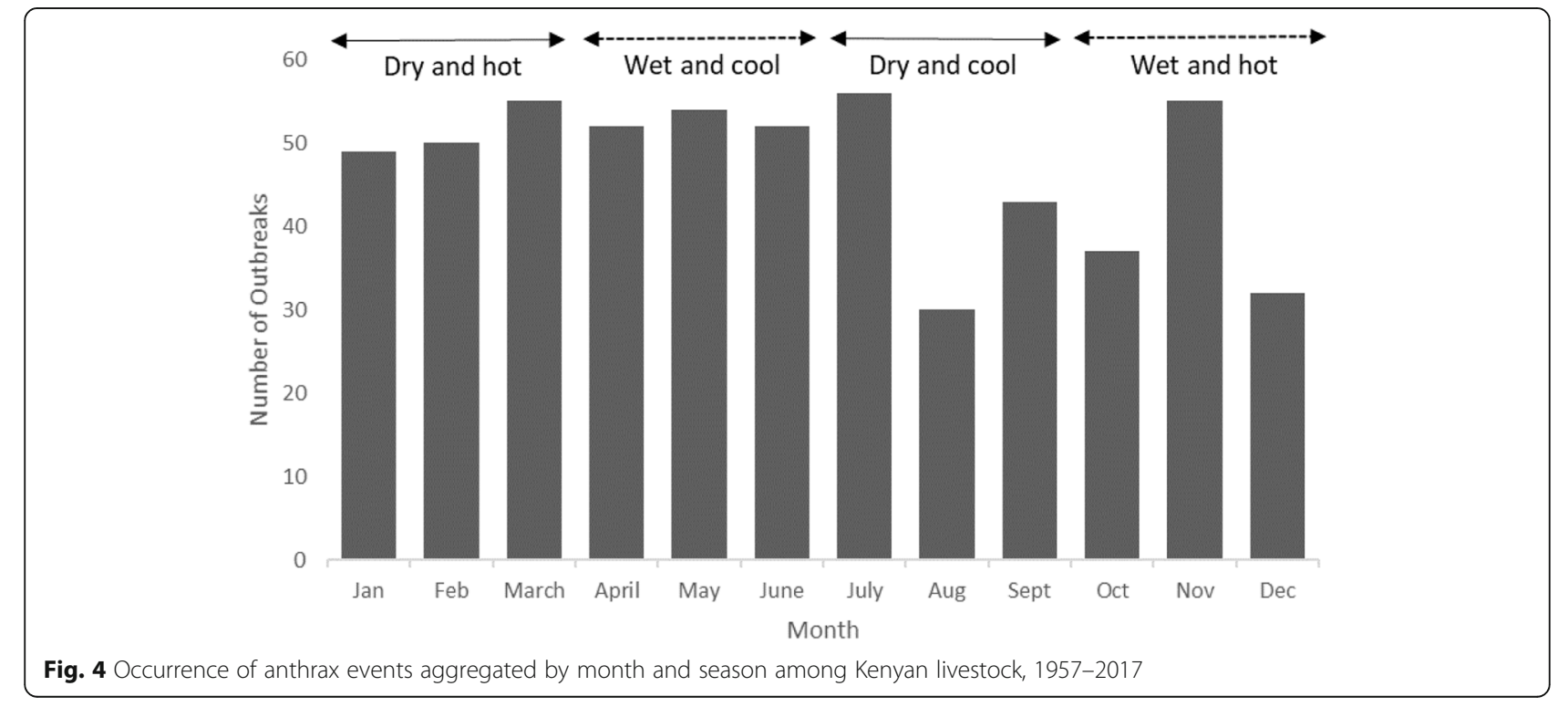




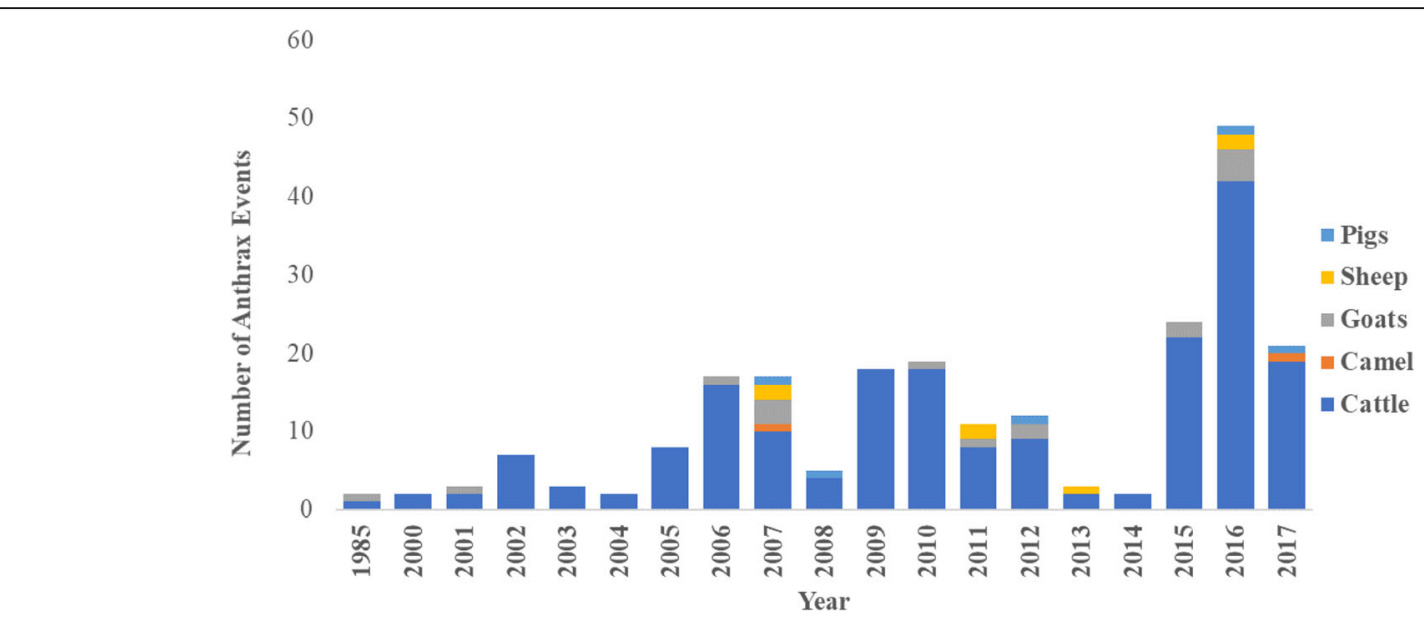

Fig. 5 Annual reported numbers anthrax events by livestock species between 1985 and 2017

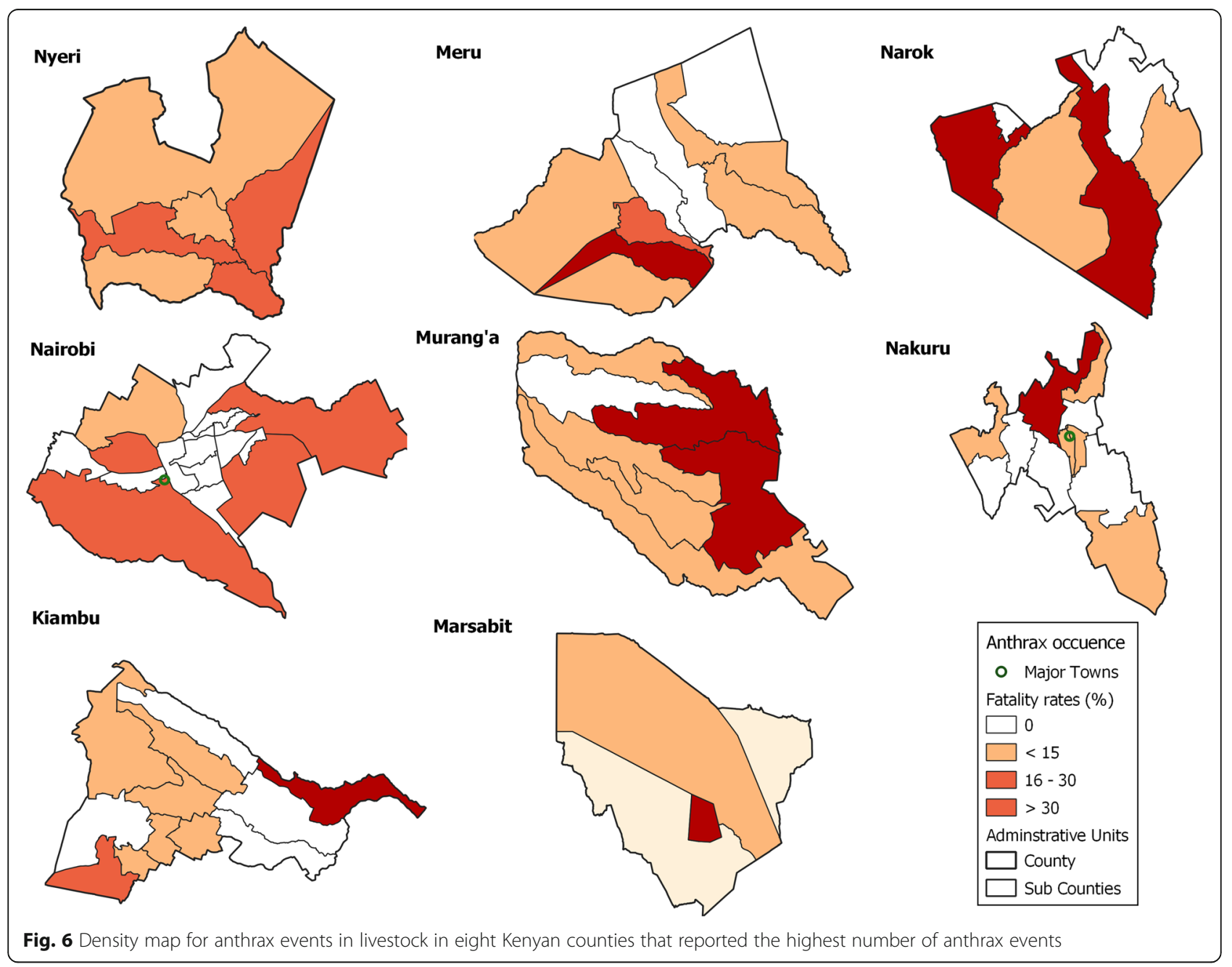




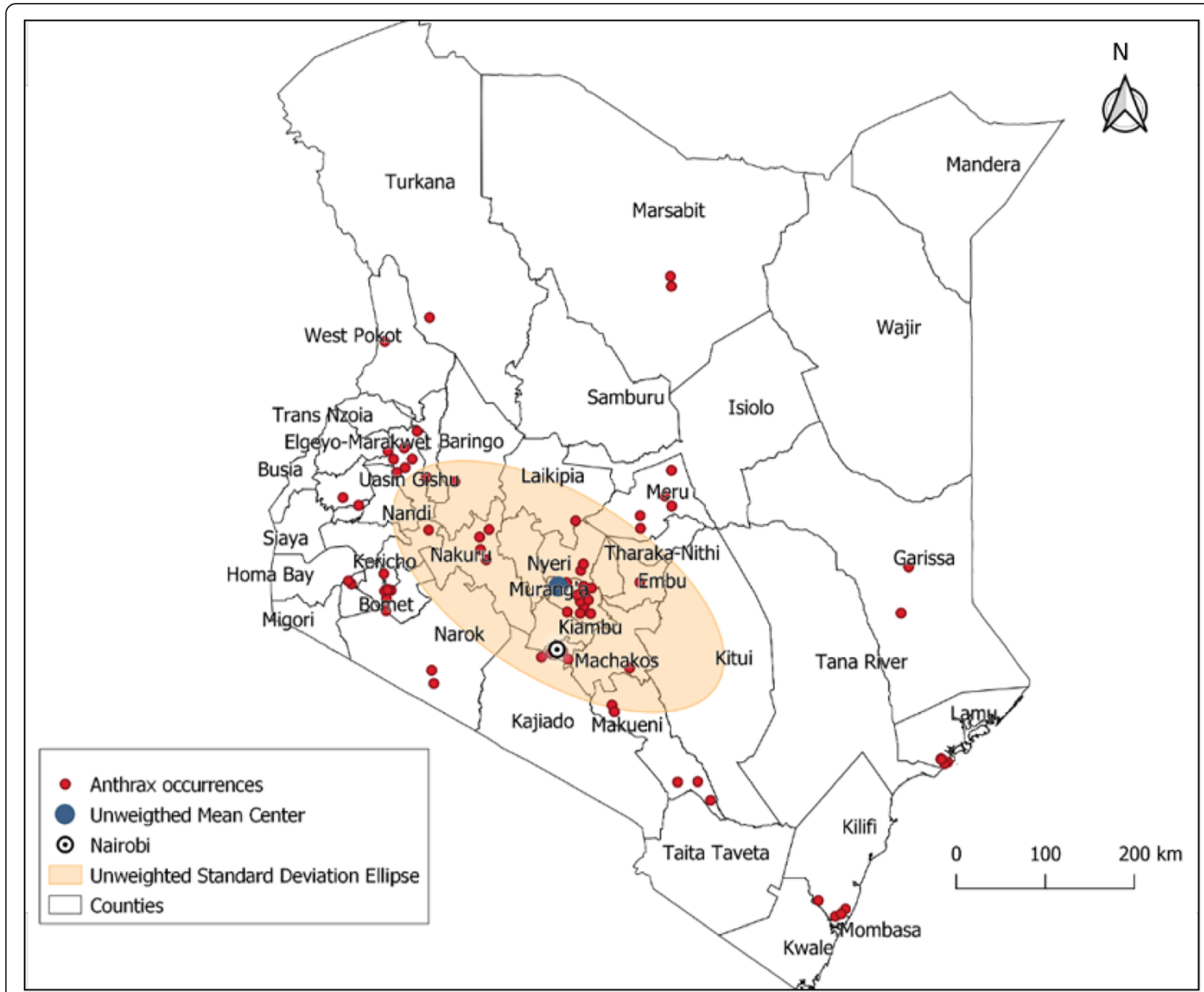

Fig. 7 Spatial distribution of the 86 anthrax events with GPS coordinates

0.000), supporting clustering at the sub-county level (Table 1). Using the 86 anthrax events, the data shows significant differences in number of events associated with calendar month using likelihood test ratio $(P=0.02$, Table 2$)$. For any given county, there was lower risk of anthrax events in August $(P=0.034)$ and December $(P=0.061)$, months preceded by long and short rain periods, respectively (Table 2). In assessing the fit of the models, the deviance statistic had a $P=0.90$ whereas the Pearson statistic had $P=$ 0.27 suggesting a good model fit.

Table 1 Assessment for spatial clustering of anthrax events using the Poisson mixed effects regression model with agro-ecological zone as fixed effect

\begin{tabular}{lllll}
\hline Variable & Variable category & Incidence rate ratio & Coefficient 95\% confidence interval & $\boldsymbol{P}$ value \\
\hline Agro-ecological zone & High and Medium potential & Reference & & \\
& Agro-alpine & 1.23 & {$[0.82,1.84]$} & 0.32 \\
& Semi-arid & 0.90 & {$[0.52,1.57]$} & 0.71 \\
& Arid & 0.48 & {$[0.23,1.00]$} & 0.05 \\
& Very Arid & 0.39 & {$[0.23,0.67]$} & $<0.001$ \\
Random effects Subcounty identification: & - & 0.72 & & - \\
\hline
\end{tabular}


Table 2 Assessment of temporal trends of anthrax events using Poisson mixed-effects regression model with calendar month as fixed effect across years

\begin{tabular}{lllll}
\hline Variable & Variable category & Coefficient & 95\% confidence interval & $P$ value \\
\hline Month & January & Reference & & \\
& February & 1.04 & {$[0.70,1.63]$} & 0.43 \\
& March & 1.11 & {$[0.77,1.65]$} & 0.55 \\
& April & 1.05 & {$[0.72,1.55]$} & 0.76 \\
& May & 1.09 & {$[0.76,1.62]$} & 0.62 \\
& June & 1.05 & {$[0.72,1.55]$} & 0.76 \\
& July & 1.13 & {$[0.79,1.67]$} & 0.49 \\
& August & 0.61 & {$[0.39,0.97]$} & 0.03 \\
& September & 0.88 & {$[0.58,1.31]$} & 0.53 \\
Random effects County identification: & October & 1.32 & {$[0.50,1.15]$} & 0.19 \\
\hline
\end{tabular}

Likelihood ratio test versus Poisson regression chibar2 $(01)=1441.2 ;$ Prob $>=$ chibar2 $=0.0000$

\section{Discussion}

This study documents a relatively high frequency ( mean $=11$ per year) and widespread distribution $(95 \%$ of the counties) of anthrax events among livestock in Kenya over 60 years, a trend similar to that reported among wildlife in the country [6]. Given that the data were derived from a passive surveillance system with significant underreporting, the actual frequency may be be two- to three-fold higher [22-25]. The anthrax events increased in recent years (since 1997), probably associated with enhanced disease surveillance and reporting by the country. The increased disease reporting is due to growing awareness of importance of timely disease detection as a measure of preparedness and response for emerging infectious diseases by the Government of Kenya, and compliance with the global animal and human health agencies such as the World Organization for Animal Health (OIE) and WHO. Similar reporting trends have been documented in other infectious diseases including influenza, viral hemorrhagic fevers, rabies and brucellosis [26-29]. A higher number of anthrax events was observed in the southwestern region of the country, possibly attributed to more developed infrastructure that promotes disease reporting, whereas the low reporting rates in arid and semi-arid marginalized northern regions of the country are likely due to poor infrastructure and access to animal health services [25].

More granular analysis at sub-county and AEZ levels showed clustering of anthrax disease events at certain locations, likely associated with the existence of geographic, ecological, and demographic risk factors that promote $B$. anthracis persistence and transmission. For instance, within eight high burden counties, $36 \%$ of the sub-counties did not report anthrax disease, whereas
$11 \%$ were responsible for $>30 \%$ of anthrax events. When analyzed by AEZ, there was significantly higher occurrence of disease in agriculturally productive zones (agroalpine, high potential, medium potential) when compared to the dry, less productive lands (semi-arid, arid, very arid). These findings are in agreement with a study in Mongolia that reported fewer anthrax cases in the arid and semi-arid areas of the country [30]. While the association between geographic factors and persistence of $B$. anthracis has been documented, the preferred AEZ appears to vary with on the global geo-climatic oscillations $[9,31]$.

The anthrax disease events were less variable when analyzed by season, even though more occurred in dry than wet seasons. We reported less anthrax events in August and December across years and counties, months that a follow the occurrence of heavy rains. This trend closely mirrored that of other studies including a wildlife study in Kenya that reported higher frequency of anthrax events in the dry season [6,10,32-34]. Of geographic factors, studies demonstrate strong correlation between rainfall and temperature with $B$. anthracis persistence and transmission, while there is less agreement on the role of soil, vegetation, population density, and other factors $[9,11,35]$.

An interesting finding in our study was the 10-fold higher anthrax events in cattle when compared to other livestock, findings similar to those reported in Australia, Lesotho, Zambia, and Zimbabwe [36-40]. Whereas it is possible that this finding represents reporting bias in favor of cattle, it may not fully explain the high levels of cattle events reported since livestock anthrax reports are closely linked with human infections that drive the reporting. It is possible that cattle are more susceptible 
to anthrax disease, perhaps due to ingesting higher doses of the pathogen because of their grazing niche, or preferential mechanical transmission of $B$. anthracis by insects and biting flies $[1,35]$. However, this is not supported by experimental challenge studies, which show sheep and goats as more susceptible than cattle [1]. The importance of the finding that cattle are more heavily affected than other livestock is that an anthrax control program involving routine vaccination of only cattle may be both effective and economically feasible.

Our study had several limitations. The use of historical data from passive surveillance represented a bias associated with higher reporting in more developed regions of the country when compared to the remote, rural, dry regions. In addition, while it was convenient to select the eight counties with the highest burden of anthrax events to investigate clustering in order to ensure sufficient numbers for analysis, this may have further exacerbated the reporting bias. The low number of anthrax events with geocodes precluded niche modeling studies to begin to tease out ecological factors important in disease occurrence. This limitation is addressed in ongoing prospective study in the country.

\section{Conclusion}

Anthrax remains a high priority zoonotic disease in subSaharan Africa associated with significant negative impact on public health and livestock productivity. The data presented here provides Kenya and the region with a roadmap for targeting surveillance, and prevention and control measures to certain AEZ, even though additional studies to support these findings are necessary.

\section{Abbreviations}

AEZ: Agro-ecological zone; B. anthracis: Bacillus anthracis; GPS: Global Positioning System; KDVS: Kenya Directorate of Veterinary Services; OIE: World Organization for Animal Health (OIE); QGIS: Quantum Geographic Information System; VEEU: Veterinary Epidemiology and Economics Unit; WHO: World Health Organization

\section{Acknowledgements}

We thank the Kenya Ministry of Agriculture, Livestock and Fisheries for granting us access to the livestock disease databases.

\section{Disclaimer}

The findings and conclusions in this report are those of the authors and do not necessarily represent the official position of the United States' Defense Threat Reduction Agency, United States' Centers for Disease Control and Prevention, or the Government of Kenya.

\section{Authors' contributions}

MKN, JG conceived the study. HO and ON provided access to the data. LMN and EGM collected the data. $L M N, B B, J G, F O$ analyzed the data. $L M N, J G$, MKN led in writing the manuscript. FO, EGM, MM, AM, EMO, IN, PMM, HO, $\mathrm{ON}, \mathrm{EL}, \mathrm{TM}, \mathrm{MAW}, \mathrm{BB}$ contributed to writing and discussion of the manuscript findings. All authors read and approved the final manuscript.

\section{Funding}

Funding for this project was provided by US Defense Threat Reduction Agency under the grant \# HDTRA11710043. The funding body had no role in the design of the study, the collection, analysis, and interpretation of data and in writing the manuscript.

\section{Availability of data and materials}

The data that support the findings of this study are available from Directorate of Veterinary Services, State Department of Livestock, Ministry of Agriculture, Livestock and Fisheries, Kenya but restrictions apply to the availability of these data, which were used under license for the current study, and so are not publicly available. Data are however available from the authors upon reasonable request and with permission of Director of Veterinary Services, Kenya.

Ethics approval and consent to participate

Administrative permissions were acquired by our team to access the data used in this paper from the Directorate of Veterinary Services, State

Department of Livestock, Ministry of Agriculture, Livestock and Fisheries, P. O Private Bag, Kangemi 00625 Nairobi, Kenya. Tel: 020-8043441.

\section{Consent for publication}

Not applicable.

\section{Competing interests}

All authors except JG declare no competing interests. JG is a member of the editorial board for the BMC Infectious Diseases journal.

\section{Author details}

'Paul G Allen School for Global Health, Washington State University, Pullman, Washington, USA. ${ }^{2}$ Washington State University Global 'Health Program-Kenya, WSU, Nairobi, Kenya. ${ }^{3}$ School of Public Health, Jomo Kenyatta University of Agriculture and Technology, Nairobi, Kenya. ${ }^{4}$ International Livestock Research Institute, Nairobi, Kenya. ${ }^{5}$ University of Nairobi, College of Agriculture and Veterinary Sciences, Nairobi, Kenya, University of Nairobi, Nairobi, Kenya. ${ }^{6}$ Kenya Zoonotic Disease Unit, Nairobi, Kenya. ${ }^{7}$ Division of Global Health Protection, United States Centers for Disease Control and Prevention, Nairobi, Kenya. ${ }^{8}$ Kenya Ministry of Agriculture, Livestock and Fisheries, Nairobi, Kenya. ${ }^{9}$ Institute of Tropical Medicine, Antwerp, Belgium.

Received: 1 July 2020 Accepted: 4 February 2021

Published online: 18 February 2021

References

1. Shadomy SV, Smith TL. Zoonosis update Anthrax. J Am Vet Med Assoc. 2008;233:63-72.

2. Bengis RG, Frean J. Anthrax as an example of the one health concept. Rev Sci Tech. 2014;33:593-604.

3. Kracalik I, et al. Human cutaneous anthrax, Georgia 2010-2012. Emerg Infect Dis. 2014;20:261-4

4. Sitali DC, Mumba C, Skjerve E, Mweemba O, Kabonesa C, Mwinyi MO, et al. Awareness and attitudes towards anthrax and meat consumption practices among affected communities in Zambia: A mixed methods approach. PLoS Negl Trop Dis. 2017;11(5):e0005580. https://doi.org/10.1371/journal.pntd. 0005580

5. Kracalik IT, Malania L, Tsertsvadze N, Manvelyan J, Bakanidze L, et al. Evidence of Local Persistence of Human Anthrax in the Country of Georgia Associated with Environmental and Anthropogenic Factors. PLOS Negl Trop Dis. 2013;7(9): e2388. https://doi.org/10.1371/journal.pntd.0002388.

6. Gachohi J, Gakuya F, Lekolool I, Osoro E, Nderitu L, Munyua P, Njenga M. Temporal and spatial distribution of anthrax outbreaks among Kenyan wildlife, 1999-2017. Epidemiology and Infection. 2019;147:E249. https://doi. org/10.1017/S0950268819001304.

7. Kasradze A, et al. Rates and risk factors for human cutaneous anthrax in the country of Georgia: national surveillance data, 2008-2015. PLoS One. 2018. 13:2008-15

8. Siddiqui MA, et al. Recent outbreak of cutaneous anthrax in Bangladesh: clinico-demographic profile and treatment outcome of cases attended at Rajshahi medical college hospital. BMC Res Notes. 2012;5:464.

9. Hugh-Jones M, Blackburn J. The ecology of bacillus anthracis. Mol Asp Med. 2009;30:356-67.

10. Turner WC, et al. Soil ingestion, nutrition and the seasonality of anthrax in herbivores of Etosha National Park. Ecosphere. 2013;4:art13. 
11. Carlson CJ, et al. The global distribution of bacillus anthracis and associated anthrax risk to humans, livestock and wildlife. Nat Microbiol. 2019;4:1337-43.

12. WHO. Anthrax in humans and animals. World Organ Anim Heal. 219, 2008. https://doi.org/10.2105/AJPH.30.3.299.

13. Omballa VO, et al. Serologic evidence of the geographic distribution of bacterial zoonotic agents in Kenya, 2007. Am. J. Trop. Med. Hyg. 2016:94:43-51.

14. Muturi M, et al. Recurrent Anthrax outbreaks in humans, livestock, and wildlife in the same locality, Kenya, 2014-2017. Am J Trop Med Hyg. 2018;99: 833-9.

15. Munyua P, Bitek A, Osoro E, Pieracci EG, Muema J, Mwatondo A, et al. Prioritization of Zoonotic Diseases in Kenya, 2015. PLoS ONE. 2016;11(8): e0161576. https://doi.org/10.1371/journal.pone.0161576.

16. Mwakapeje ER, et al. Anthrax outbreaks in the humans - livestock and wildlife interface areas of northern Tanzania: a retrospective record review 2006-2016. BMC Public Health. 2018;18:106.

17. Microbiology Services. UK standards for microbiology investigations. Bacteriology. 2015;9:1-27.

18. QGIS. Delopment team. Open Source Geospatial Foundation: QGIS Geographic Information System; 2015.

19. Austin PC. Measures of clustering and heterogeneity in multilevel Poisson regression analyses of rates / count data. 2018:572-89. https://doi.org/10.1 002/sim.7532.

20. Alegria-Moran R, Miranda D, Barnard M, Parra A, Lapierre L. Characterization of the epidemiology of bat-borne rabies in Chile between 2003 and 2013. Prev Vet Med. 2017:143:30-8.

21. KNBS. "Economic survey", Kenya National Bureau of Statistics. 2009; available at: www.knbs.or.ke/publications/ES2009MinisterPresentation. pdf?SQMSESSID.

22. Rosenthal S, Chen R. The reporting sensitivities of two passive surveillance systems for vaccine adverse events. Am J Public Health. 1995;85(12):1706-9. https://doi.org/10.2105/AJPH.85.12.1706.

23. Vogt RL, LaRue D, Klaucke DN, Jillson DA. Comparison of an active and passive surveillance system of primary care providers for hepatitis, measles, rubella, and salmonellosis in Vermont. Am J Public Health. 1983;73(7):795-7. https://doi.org/10.2105/AJPH.73.7.795.

24. Sutter RW, Cochi SL. Pertussis hospitalizations and mortality in the United States, 1985-1988: evaluation of the completeness of National Reporting. JAMA J Am Med Assoc. 1992. https://doi.org/10.1001/jama.1992.03480030064038.

25. Allen T, et al. Global hotspots and correlates of emerging zoonotic diseases. Nat Commun. 2017:8:1-10.

26. Murithi RM, et al. Rift Valley fever in Kenya: history of epizootics and identification of vulnerable districts. Epidemiol Infect. 2010;139:372-80

27. Osoro EM, et al. Hospitalized patients with pandemic (H1N1) 2009, Kenya. Emerg Infect Dis. 2011;17:1744-6.

28. Ogola E, Thumbi S, Osoro E, Munyua P, Omulo S, Mbatha P, Ochieng L, Marwanga D, Njeru I, Mbaabu M, Wanyoike S, Njenga K. Sero-prevalence of Brucellosis in Humans and their Animals: A Linked Cross-sectional Study in Two Selected Counties in Kenya. Online J Public Health Inform. 2014;6(1): e67. https://doi.org/10.5210/ojphi.v6i1.5166.

29. Bitek $A O$, et al. A hundred years of rabies in Kenya and the strategy for eliminating dog-mediated rabies by 2030. AAS Open Res. 2019. https://doi. org/10.12688/aasopenres.12872.2.

30. Odontsetseg N, Sh T, Adiyasuren Z, Uuganbayar D, Mweene AS. Anthrax in animals and humans in Mongolia. Revue Scientifique et Technique (International Office of Epizootics). 2007;26(3):701-10

31. Mullins JC, et al. Ecological niche modeling of bacillus anthracis on three continents: evidence for genetic-ecological divergence? PLoS One. 2013;8:e72451.

32. Munang'andu $\mathrm{HM}$, et al. The effect of seasonal variation on anthrax epidemiology in the upper Zambezi floodplain of western Zambia. J Vet Sci. 2012;13:293-8

33. Lepheana RJ, Oguttu JW, Qekwana DN. Temporal patterns of anthrax outbreaks among livestock in Lesotho, 2005-2016. PLoS One. 2018;13:2005-16.

34. Chikerema SM, Pfukenyi DM, Matope G, Bhebhe E. Temporal and spatial distribution of cattle anthrax outbreaks in Zimbabwe between 1967 and 2006. Trop Anim Health Prod. 2012;44:63-70

35. World Health Organization, Food and Agriculture Organization of the United Nations, W. \& Health. Anthrax in humans and animals. (2008).

36. Rao $\mathrm{S}$, et al. Risk factors associated with the occurrence of anthrax outbreaks in livestock in the country of Georgia: a case-control investigation 2013-2015. PLoS One. 2019;14:1-16.
37. Lepheana RJ, Oguttu JW, Qekwana DN. Temporal patterns of anthrax outbreaks among livestock in Lesotho, 2005-2016. PLoS One. 2018. https:// doi.org/10.1371/journal.pone.0204758.

38. Turner AJ, Galvin JW, Rubira RJ, Miller GT. Anthrax explodes in an Australian summer. J Appl Microbiol. 1999. https://doi.org/10.1046/j.1365-2672.1999. 00869.x.

39. Blackburn JK, et al. Modeling the Ecological Niche of Bacillus anthracis to Map Anthrax Risk in Kyrgyzstan. 2017;96:550-6.

40. Wilson JM, Brediger W, Albright TP, Smith-Gagen J. Reanalysis of the anthrax epidemic in Rhodesia, 1978-1984. PeerJ. 2016;4:e2686.

\section{Publisher's Note}

Springer Nature remains neutral with regard to jurisdictional claims in published maps and institutional affiliations.
Ready to submit your research? Choose BMC and benefit from:

- fast, convenient online submission

- thorough peer review by experienced researchers in your field

- rapid publication on acceptance

- support for research data, including large and complex data types

- gold Open Access which fosters wider collaboration and increased citations

- maximum visibility for your research: over $100 \mathrm{M}$ website views per year

At BMC, research is always in progress.

Learn more biomedcentral.com/submissions 